\title{
PHR, we've had a problem here
}

\author{
Minna M. Rantanen ${ }^{1 \text { [0000-0001-8832-5616] }}$ and Jani Koskinen ${ }^{1 \text { [0000-0001-8325-9277] }}$ \\ ${ }^{1}$ Information Systems Science, Turku School of Economics, University of Turku \\ minna.m.rantanen@utu.fi
}

\begin{abstract}
Personal health records (PHRs) have been a global trend in recent decade. It has been seen as a concept and tool that could help patients maintaining health, improving their well-being, and supporting communication with healthcare professional etc. Despite the great amount of research about PHR there is no consensus what a PHR actually means in academic literature or other arenas. There are multiple terms in use and multiple definitions which set challenges for rational discourse between citizens/patient, healthcare providers, system developers and policy makers. Especially, when citizens - as key stakeholder - should also be able to understand what those systems are we need clear and understandable definition for PHR's. In the paper, we conduct a brief survey for different definitions and show the problems that arise with the incoherent use of the term "PHR".
\end{abstract}

Keywords: Personal Health Record, PHR, definition, rational discourse, quasirational discourse.

\section{Introduction}

Rantanen and Heimo [1] state in their article about definition of term patient information system (PIS): "To have a discussion with one another we require a common set of terms understood by everyone. To develop complex multidisciplinary information systems we need a possibility for discussion. To enhance our level of healthcare we require complex multidisciplinary information systems. Thus, the further development of terminology in the subject is not only recommended but required."

The same statement applies to all terms in field of health related informatics ${ }^{1}$. The need for clearing the terminology of health informatics and health information technology is pointed out by several authors [2]. Besides PIS, terms like eHealth, electronic medical record (EMR) and electronic health record (EHR) have had their share of critique about vagueness and multiple meanings [3-5]. Also definition of personal health record (PHR) - or lack of it — has been noted before [6-9]. However, there is still no consensus about what does the term PHR mean or what separates it from several similar terms used to describe information systems for health information management.

1 Medical informatics, nursing informatics, health informatics, etc. Note that field(s) itself has not been able to create the common name for the research area. 
Although many scholars seem to agree, that there indeed is a problem with terminology in health informatics, not all share this view. For example, Coiera [10, p. 113] states that "With such a wide variation in the functions that could be expected from an EMR, it is probably unwise to try to define the EMR in any formal way. It is more fruitful to observe that there are a range of clinical activities that use and communicate information, and that some of these can be supported through the introduction of technology.".

However, there are several problems if we accept situation where term are not properly defined. By accepting unclear terms we lack of common ground for discussion, face problems of interpreting the current literature etc. We will focus those problems in more detail later in this paper. However, we want to note it shortly here: to solve problems we need to have a discussion, and to have meaningful discussion participants need to have the same understanding about the used terms - in this case about the term PHR. It seems that based on confusing use of terms in academic literature we have ended up in situation where understating about PHR is obscured: our academic discourse/understanding is blurred and political communication can be even claimed to be infertile.

In this paper, we focus on the definition of PHR and problems that lack of definition creates. In the second section, we will give insight to background of PHRs and role of those in the healthcare and health(care) informatics. In the third section, we present the state of incoherence in the PHR term use and present some variation of the term $^{2}$. In the fourth section, we present examples of problems that these several conceptualizations and vague definitions of PHR create for public discussion and academic research. In the fifth section, we are using Habermas [11, 12] as source for our consideration for needed discourse and to highlight the need for consensus about terms and their definitions. In the final chapter, we draw the conclusions and shed light on our future research.

\section{Background of PHRs}

In today's society, healthcare is changing from doctor centered to consumer centered service, where individuals are authorities of their own health instead of being mere passive patients [13]. Thus, the patients are more and more seen as customers that must be served. This has set the need for information systems used in healthcare and PHR is getting more and more attention as it has this personal aspect build in $[14,15]$. Shared decision-making and PHRs as part of it is seen as promising approach in healthcare even it has not achieve the expectations [16]. Therefore, PHR can be reasonably seen as central technology and concept for patient/customer/citizen -oriented healthcare in this patient-centered and even individualist era of healthcare.

Simultaneously, paradigm of healthcare is moving - or at least it should be from sickness centered care towards preventive care where the aim is to support the health of individual and hence help them to achieve personal plans [17-20]. Thus, in

2 Even the claim that those terms are variation of PHR is actually inconsistent with spirit of this paper that seeks the clear terminological coherence of life 
modern society individuals are seen more and more as experts of their own health and as the ones, who should be the ones taking care of their well-being in sickness and in health - although they still may need support from medical professionals.

Internet and web-based services have allowed people access vast amount of information about well-being, that traditionally has been a privilege of medical professionals. It has been argued that also people's perception of health has shifted toward more holistic view, and that they are actually more interested in gathering information about their health. $[18,21,22]$ Simultaneously, technological development has made it also easier to track and measure one's health. An extreme example of this is the rise of the bio-hacker culture [23].

More modest example is the popularity of personal health records (PHRs) among healthcare service providers. Many countries, researcher and healthcare organizations seem to believe, that PHRs are the solution to the sustainability gap of public healthcare system [23, 24, 22]. However, lack of inter-operationality between EHRs and PHRs still exists, even though the first notions of PHRs can be traced back to the late 1970s [25]. Likewise, even though there has been effort to increase the use of PHRs the adoption rate has been low [26].

Nevertheless, healthcare is under pressure to become more efficient due to aging of the population, which is assumed to decrease available funding as well as increase demand of healthcare services [20]. PHRs are seen as solutions that offer several benefits that can help to achieve more sustainable healthcare [?]. In theory, users of PHRs can get more accurate health information, monitor their own health and communicate easier with healthcare professionals [22, 27, 28].

These theoretical benefits are seen as gateway to more efficient and sustainable healthcare, since it is assumed that by focusing on more preventive measures and by providing people self-treatment instructions the demand of healthcare will decrease [29]. Some studies have shown that use of PHRs may be a key component when designing new models of healthcare. It has been shown that in case of chronically ill patients, PHRs have provided better coordination of care, communication and patient empowerment as well as decreased need for consulting a doctor. [22, 27, 29]

Besides effects that will rise from more autonomous patients, wider utilizing of PHRs is seen as an action that will benefit also healthcare professionals. In theory, if patients use PHRs, healthcare professional will get more accurate information to work on and thus, the quality of treatment will improve. [6,29] Thus, PHRs are often represented as a simple (technical) solution to a major problem facing healthcare. However, as we can see from the past, problems with efficiency in healthcare have rarely been solved by simple implementation of an information system [30-33]. In healthcare, careless attempts to change the healthcare system by implementing a technical system, have in the worst-case scenarios led to loss of human lives - such as in case of London Ambulance service [34].

It must be remembered, that this example is extreme and more often the consequences are less severe. For instance, it has been studied that promoted benefits of electronic medical records (EMR) such as efficiency and cost savings are rarely met, because these systems are not designed to support the processes of healthcare professionals, but rather to full-fill the idea of new and efficient process [30, 32, 35]. Thus, 
it could be beneficial to conduct more user-centered design and development of these kinds of systems to acknowledge social dimension.

In case of PHRs, majority of users are not medical professionals but individuals that have varying knowledge, motivations and goals when using these systems. User groups can vary from individuals that live specific chronic condition to whole nations [33]. This makes the users of PHRs more heterogeneous group than for instance the users of EMRs and thus, conducting a user-centered design and development more challenging.

Since many countries are currently developing their public healthcare with implementation of PHRs [33], we argue that it should be possible to develop these systems based on public discussion. This discussion should allow willing citizens to participate on development of governmental PHRs, so that these systems would serve them in the best possible way and make it possible to reach more sustainable healthcare that is seen as goal of national PHR development.

\section{Different Terms and Various Meanings}

The wide use of term PHR's is evident and intuitively it can seems to be quite straightforward term to use. However, the PHR is concept that is neither unambiguous or generally defined but instead has long and changeable history. [13] Although PHRs have been lately discussed as something new and innovative, in reality the concept has been first used in the late 1960s. During the 1970s and 1980s term PHR was used in the literature referring the paper-based document that was carried by individual. During these decades cases research was focusing to some group of people - as young female students in Japan - or some social concerns as maternal and child health [13].

We claim that the 1990s was a decade when it really started to be noted and new millennium is time when it popped up to be a mainstream term of healthcare (IS) research. In the 1990s the PHR was used also as "patient-held health record" and this idea of patient-held approach has been trend in literature even there was also other derivatives of term PHR [13]. Nowadays it seems that term PHR is stabilized to mean personal health records.

The problem is same for the whole area of healthcare information system research we do not have common definition for acronyms that are used in research [5,6,1]. In other words, it seems that field do not have common understanding about the terms. In most cases articles using terms - as PHR, EHR etc. — are not using any clear definition. However, there are some occasionally, but not systematically, used definitions of PHR. In addition that we have different meanings for term PHR there found different variants/modification for it such as:

- interactive preventive health record (IPHR) [36]

- electronic personal health record (ePHR) [37]

- personally controlled health management systems (PCHMS) [38]

- mobile personal health records (mPHR) [15]

- personal health record application (PHA) [39] 
- self-management mobile personal health record (SmPHR) [40]

- personal electronic health records (P-EHR) [41]

Likewise, there are commonly used two categories for PHR's: Tethered PHR's that are part of EHR or at least connected to it and Stand-alone ones that are independent records even the categories can overlap [6]. There exists somewhat known and used definitions for PHRs even those still cannot seen that they have established position or recognition in the field of Health informatics. For instance, definitions from Markle Foundation are to some extend used in scientific literature.

Markle foundation: "A PHR is an Internet-based set of tools that allows people to access and coordinate their lifelong health information and make appropriate parts of it available to those who need it" [42] and "an electronic application through which individuals can access, manage and share their health information, and that of others for whom they are authorized, in a private, secure, and confidential environment." [43]

There are, however, some problems with these definitions. These definitions $[42,43]$ suggest, that PHR cannot be anything else than an electronic system. This is problematic, since individuals can, and probably do, also store information about their health on paper [44]. Thus, defining PHR as "internet-based" or as "an electronic application" is too narrow to grasp the full spectrum of PHRs, which have been and still can be also analogical systems.

First definition of Markle Foundation [42], also suggests that in order to a system be a PHR, the information should cover the whole life of individual. This is rather optimistic idea since some PHRs can be linked to local patient information systems, and thus, information can be limited to specific time that individual has lived in that area. Even if PHR is not limited to certain area, it is not likely that an individual would use the same system their whole life, since people are keen to try new systems in order to find one that fits their needs [23].

Markle Foundation's second definition [43] does also suggest, that a PHR is a PHR only if it is in "private, secure, and confidential environment". Since, health information is private information, these attributes should be noted when designing a PHR. Nevertheless, it cannot be stated that a PHR is not a PHR, when it is a target of hacking or its environment is otherwise compromised. Thus, private, secure and confidential environment is only a preferable characteristic of PHR, not one that defines it.

For instance, International Organization for Standardization (ISO) has also made an effort to form a definition for PHR. Although earlier definitions share the problems of being limited to electronic PHRs and desirable features [22], the updated version from 2014 avoids these problems.

ISO definition: "PHR representation of information regarding or relevant to the health, including wellness, development, and welfare of a subject of care, which may be stand-alone or integrating health information from multiple sources, and for which the individual, or their authorized representative, manages and controls the PHR content and grants permissions for access by and/or sharing with other parties" [45]

This definition of ISO does not limit PHRs to electronic systems, does not assume that a PHR contains lifelong information, and it does not mix preferable characteris- 
tics with fundamental aspects. However, this particular version from 2014 has been rarely used in the scientific papers. It could serve as a good ground definition to PHR - if it would be used. However, there is still need to analyze this definition and its relation to other terms used, since it might not sufficient to cover them all.

\section{Problems and Challenges}

The aforementioned heterogeneous use of term will harm research on PHR's as we lack the common agreement or understanding what PHRs actually are. In some articles PHR can mean the extension for EHR so that patient has possibility to see their patient information and in some occasions manage their information. However, in another article PHR is seen as stand-alone system for collecting information about one's health. Thus, despite the efforts made in defining this term, there is a conceptual vacuum that can create misunderstandings and other problems.

Besides there being many different definitions in scientific writings there is also a problem of not defining what is meant by PHR [13, 46, 47]. This, we argue, is more severe problem than using any of the existing definitions or creating a yet another definition. This is a major problem due to variety of different definitions and interpretations that people can have. Hence, when definition is not given, readers can interpret the term PHR in different way that the writers would have assumed. Misinterpretations can lead to misinterpretation of the whole written work and thus, undermine its purpose.

This also creates a problem of comparability, since without knowing the implicit interpretation about PHR that different authors have, we cannot compare the results $[1,48]$. For example, if one author claims that PHRs have been beneficial in certain situation and other claims opposite and both have neglected defining the PHR, can we trust that they are talking about same kind of PHR? On the other hand, also use of different definitions and variety similar terms makes it hard to compare and combine results in whole research area. This causes unnecessary fragmentation of research, that could be solved with consensus about terms and definitions used in literature. As mentioned, some definitions have gained more popularity than others in scientific community, but there are major differences between them.

It could be also claimed, that many of these definitions fail to capture some fundamental aspects of PHRs or, on the contrary, focus on irrelevant aspects that are not fundamental as noted earlier. On the other hand, the definition by ISO [45] — which seems to grasp the basic idea of PHR - has not been taken into use. Instead, there is an unfortunate habit of not stating what is meant by the term PHR. Existence of multiple definitions, lack of definitions and variety of interpretations force us down to conceptual analysis of the essence of PHR - a laborious task that should be conducted in another paper.

These problems do not limit to the scientific community alone. If scientific community has disagreements and contradictory interpretations about the definition of PHR, it can be assumed that laymen have no better understanding what is meant by this concept. Since PHRs are affecting and will be affecting large masses of people in 
the future, there should be a possibility to understand these systems that will handle their private health information.

Development of national PHRs highlights the need for clear and commonly understood definition of PHR. As said, PHRs affect and will affect many people in the future and to develop them we should be able to discuss about them not only among professionals, but also with people that are or will be ones to use them [33]. The lack of definition or the lack of consensus about the meaning of PHR is a barrier of having a meaningful discourse, since people having the conversation could have very different interpretation about what is a PHR in the first place.

\section{$5 \quad$ Rational vs Quasi-Rational Discourse}

As basis for meaningful discourse we are using the rational discourse by Habermas where all subjects of legislation have possibility to take part in discourse [11]. The Habermasian rational discourse is based on arguments which are evaluated by rationality and plausibility. Those arguments can be based on logic, ethics, or other justified basis. The condition for rational discourse is that no strategic games are allowed in it. A strategic game is a way of using power against others by using something other than a better argument as bargain, and this is not allowed. Like Lyytinen and Hirschheim [49] shows, the Habermas's rational discourse is promising approach for understanding social aspects of IS. Especially important is the idea that norms should be formed through discourse in which every stakeholder is given a possibility to be involved [11].

Thus, the rational discourse is way to act where agreement can be forged. Discourse has four criteria to be described as rational one. Those are clarity, truthfulness, correctness and appropriateness. In addition for those criteria, there certain ground rules. First, actor have possibility to participate discourse and express their arguments. Secondly, all actors need to accept the better and thus more rational argument over inferior one [11]. These four criteria are used as basis of rationality and thus can be used to analyze current discourse about PHRs in the public sphere [12] and also in the academic literature.

However, even Habermasian discourse is just an ideal state and may not be ever reached, it does not mean that we should abandon idea. If we not even try to reach this rationality, we are prisoners of quasi-rational discourse. By Quasi-rationality we are referring to discourse that can by first view seem to be rational one but actually is based on nonsense, jargon and in best scenario; bad interpretation of evidence [50].

In case of national PHRs it we argue, that it is not recommended, but required to make discussion possible especially in democratic countries. However, this task cannot be left solely too governmental officials, who too often have no experience in the field of information systems and tend to make definitions that do not grasp the full nature of an information system [33]. Instead the political discussion is in many cases based on jargon, nonsense and quasi-rationality [50]. 


\section{Conclusion}

As shown before we can state that healthcare is evolving together with - or because - technological development. However, it seems that high expectations laid upon information technologies as solution for challenges of healthcare are not met. Especially, PHRs are seen as solutions that have momentum to make people more active, informed and at the end healthy.

The problem is that we do not even know what we are referring with the term PHR. When literature of health informatics is missing common terminology it means that it is actually impossible make comparison between conducted research as focus of those can be on different kind of systems even terms as similar. This has consequences as research findings can be contradictory. If one research sees PHR as standalone memo made by individual and other sees it as extension of EHR (used by healthcare professionals) where patient access to see part of their medical information, the conclusion most likely will differ. Using different terms as synonyms is not helpful either.

Thus, we have a problem here. The terms used in field of health informatics should be carefully analyzed and clearly defined so that we can discuss these matters. We should find a consensus about meaning of the term PHR, so that we could develop these systems to be better and to do so, we should also make it possible to the users to participate in the meaningful discussion.

This means that we need to review the terms and definitions used in literature systemically. In future research we are aiming to conduct systematic review of main terms like PHR and EHR. The long term goal is to create ontology of health informatics terminology based on these reviews. In addition to that, there is need to persuade the researchers of the field to start use those defined terms that ontology offers and also engage those researchers to develop that ontology in future in a meaningful way.

\section{References}

1. Rantanen, M.M., Heimo, O.I. Problem in Patient Information System Acquirement in Finland: Translation and Terminology. In: Kimppa K., Whitehouse D., Kuusela T., Phahlamohlaka J. (eds) ICT and Society. HCC 2014. IFIP Advances in Information and Communication Technology, vol 431. Springer Berlin Heidelberg, Berlin, Heidelberg (2014) 362-375

2. Hersh, W.: A stimulus to define informatics and health information technology. BMC Medical Informatics and Decision Making 9(1) (May 2009) 24

3. Garets, D., Davies, M.: Electronic Patient Records EMRs and EHRs Concepts as different as apples and oranges at least deserve separate names. Healthcare Informatics online October 2005 (2005)

4. Oh, H., Rizo, C., Enkin, M., Jadad, A.: What is eHealth (3): A systematic review of published definitions. J Med Internet Res 7(1) (Feb 2005) e1

5. Häyrinen, K., Saranto, K., Nykänen, P.: Definition, structure, content, use and impacts of electronic health records: A review of the research literature. International Journal of Medical Informatics 77(5) (2008) $291-304$ 
6. Tang, P.C., Ash, J.S., Bates, D.W., Overhage, J.M., Sands, D.Z.: Personal Health Records: Definitions, Benefits, and Strategies for Overcoming Barriers to Adoption. Journal of the American Medical Informatics Association 13(2) (2006) 121-126

7. Kaelber, D.C., Jha, A.K., Johnston, D., Middleton, B., Bates, D.W.: A research agenda for personal health records (PHRs). Journal of the American Medical Informatics Association 15(6) (2008) 729-736

8. Reti, S.R., Feldman, H.J., Safran, C.: Governance for Personal Health Records. Journal of the American Medical Informatics Association 16(1) (2009) 14-17

9. Thompson, M.J., Reilly, J.D., Valdez, R.S.: Work system barriers to patient, provider, and caregiver use of personal health records: A systematic review. Applied Ergonomics 54 (2016) $218-242$

10. Coiera, E.: Guide to Health Informatics. 2nd ed. London, Great Britain: Hodder Arnold (2003)

11. Habermas, J.: Between Facts and Norms: Contributions to a Discourse Theory of Law and Democracy. MIT Press (1996)

12. Habermas, J.: The Public Sphere: An Encyclopedia Article. Media and cultural studies: Keyworks (2001) 102-107

13. Kim, J., Jung, H., Bates, D.W.: History and Trends of "Personal Health Record" Research in Pubmed. Healthc Inform Res 17(1) (2011) 3-17

14. Lahtiranta, J., Koskinen, J.S.S., Knaapi-Junnila, S., Nurminen, M.: Sensemaking in the Personal Health Space. Information Technology \& People 28(4) (2015) 790- 805

15. Lee, G., Joong, Y.P., Soo-Yong, S., Jong, S.H., Hyeon, J.R., Jae, H.L., Bates, D.W.: Which Users Should be the Focus of Mobile Personal Health Records? Analysis of User Characteristics Influencing Usage of a Tethered Mobile Personal Health Record. Telemedicine and e-Health 22 (2016) 419-428

16. Davis, S., Roudsari, A., Raworth, R., Courtney, K.L., MacKay, L.: Shared Decisionmaking Using Personal Health Record Technology: a Scoping Review at the Crossroads. Journal of the American Medical Informatics Association 24(4) (2017) 857-866

17. Antonovsky, A.: The Salutogenic Model as a Theory to Guide Health Promotion. Health Promotion International 11(1) (1996) 11-18

18. Lahtiranta, J.: Current Challenges of Personal Health Information Management. Journal of Systems and Information Technology 11(3) (2009) 230-243

19. Akter, S., D'Ambra, J., Ray, P.: Development and Validation of an Instrument to Measure User Perceived Service Quality of mHealth. Information \& Management 50(4) (2013) 181 $-195$

20. Demiris, G.: New Era for the Consumer Health Informatics Research Agenda. Health Systems 1(1) (2012) 13-16

21. Piras, E.M., Zanutto, A.: "One day it will be you who tells us doctors what to do!". Exploring the "personal" of PHR in pediatric diabetes management. Information Technology \& People 27(4) (2014) 421-439

22. Caligtan, C.A., Dykes, P.C.: Electronic health records and personal health records. Seminars in Oncology Nursing 27(3) (2011) 218 - 228 Patient-Centered Technologies: Enhancing Communication and Self-Care for Patients and Caregivers.

23. Holopainen, A.: Mobiiliteknologia ja terveyssovellukset, mitä ne ovat? Duodecim 131(13) (2015) 1285-90

24. Househ, M.S., Borycki, E.M., Rohrer, W.M., Kushniruk, A.W.: Developing a Framework for Meaningful Use of Personal Health Records (PHRs). Health Policy and Technology 3(4) (2014) 272 - 280 
25. Heart, T., Ben-Assuli, O., Shabtai, I.: A review of PHR, EMR and EHR integration: A more personalized healthcare and public health policy. Health Policy and Technology 6(1) (2017) 20-25

26. Ozok, A.A., Wu, H., Gurses, A.P.: Exploring patients' use intention of personal health record systems: Implications for design. International Journal of Human-Computer Interaction 33(4) (2017) 265-279

27. Dullabh, Prashila; Sondheimer, N.K.E., Evans, M.A.: How patients can improve the accuracy of their medical records,. eGEMs 2(3) (2014)

28. Bonander, J., Gates, S.: Public health in an era of personal health records: Opportunities for innovation and new partnerships. J Med Internet Res 12(3) (Aug 2010) e33

29. Genitsaridi, I., Kondylakis, H., Koumakis, L., Marias, K., Tsiknakis, M.: Evaluation of personal health record systems through the lenses of EC research projects. Computers in Biology and Medicine 59 (2015) 175-185

30. Weis, J.M., Levy, P.C.: Copy, paste, and cloned notes in electronic health records. Chest 145(3) (2014) $632-638$

31. Chao, C.A.: The Impact of Electronic Health Records on Collaborative Work Routines: A Narrative Network Analysis. International Journal of Medical Informatics 94 (2016) 100 111

32. Bushelle-Edghill, J., Brown, J.L., Dong, S.: An examination of EHR implementation impacts on patient-flow. Health Policy and Technology 6(1) (2017) $114-120$

33. Rantanen, M.M.: Terveydenhuollon digitalisaatio sosioteknisestä näkökulmasta. Master's thesis, Turku School of Economics (2017)

34. Dobson, J.: Understanding failure: The London Ambulance Service Disaster. In Dewsbury, G., Dobson, J., eds.: Responsibility and Dependable Systems. Springer London, London (2007) 130-161

35. Chaudhry, B., Wang, J., Wu, S., et al: Systematic review: Impact of health information technology on quality, efficiency, and costs of medical care. Annals of Internal Medicine 144(10) (2006) 742-752

36. Kerns, J.W., Krist, A.H., Longo, D.R., Kuzel, A.J., Woolf, S.H.: How patients want to engage with their personal health record: a qualitative study. BMJ Open 3(7) (2013)

37. Kogut, S.J., Goldstein, E., Charbonneau, C., Jackson, A., Patry, G.: Improving medication management after a hospitalization with pharmacist home visits and electronic personal health records: an observational study. Drug Healthc Patient Saf 6 (2014) 1-6

38. Lau, A., Dunn, A., Mortimer, N., Proudfoot, J., Andrews, A., Liaw, S., Crimmins, J., Arguel, A., Coiera, E.: Consumers' online social network topologies and health behaviours. In Lehmann, C., Ammenwerth, E., Nøhr, C., eds.: MEDINFO 2013. Volume 192 of Studies in Health Technology and Informatics., Netherlands, IOS Press (2013) 77-81

39. Massoudi, B.L., Olmsted, M.G., Zhang, Y., Carpenter, R.A., Barlow, C.E., Huber, R.: A eb-based intervention to support increased physical activity among at-risk adults. Journal of Biomedical Informatics 43(5, Supplement) (2010) S41 - S45 Project HealthDesign.

40. Park, H.S., Cho, H., Kim, H.S.: Development of a Multi-agent m-Health Application Based on Various Protocols for Chronic Disease Self-management. J. Med. Syst. 40(1) (January 2016) 1-14

41. Santos, C., Pedrosa, T., Costa, C., Oliveira, J.L.: Concepts for a personal health record. Studies in health technology and informatics 180 (2012) 636-640

42. Markle Foundation: The personal health working group final report. http://www.providersedge.com/ehdocs/ehr_articles/The_Personal_Health_Working_Group _Final_Report.pdf (2003) 
43. Markle Foundation: Connecting Americans to their health care: A common framework for networked personal health information. http://www.markle.org/sites/ default/files/CFConsumers-Full.pdf (2006)

44. Davidson, E.J., Østerlund, C.S., Flaherty, M.G.: Drift and shift in the organizing vision career for personal health records: An investigation of innovation discourse dynamics. Information and Organization 25(4) (2015) 191 - 221

45. International Organization for Standardization: ISO/TR 14639-2:2014(en). https: //www.iso.org/obp/ui/\#iso:std:iso:tr:18638:ed-1:v1:en:te (2014)

46. Tang, P.C., Lansky, D.: The missing link: Bridging the patient-provider health information gap. Health affairs 24(5) (Sep 2005) 1290-5

47. Arens-Volland, A.G., Spassova, L., Bohn, T.: Promising approaches of computer supported dietary assessment and management — current research status and available applications. International Journal of Medical Informatics 84(12) (2015) 997 - 1008

48. Valta, M.: Sähköisen potilastietojärjestelmän sosiotekninen käyttöönotto: seitsemän vuoden seurantatutkimus odotuksista omaksumiseen. PhD thesis, University of Eastern Finland, Faculty of Social Sciences and Business / Department of Health and Social Management (2013)

49. Lyytinen, K., Hirschheim, R.: Information systems as rational discourse: An application of Habermas's theory of communicative action. Scandinavian Journal of Management 4(1) (1988) 19-30

50. Koskinen, J., Rantanen, M.M.: Discourse about governmental eHealth information systems — jargon, non-sense and quasi-rationality. In: Ethicomp 2018. (2018 in print) 